\title{
Comparison of affinity ranking and immunochemical key data as measure for molecular antibody evolution
}

\author{
Karl Kramer*, Doris Rau and Bertold Hock \\ Chair of Cell Biology, Center of Life Sciences Weihenstephan, Technische Universität München, \\ Alte Akademie 12, D-85350 Freising, Germany
}

\begin{abstract}
The evolutionary optimization of antibody binding properties in vitro opens new perspectives for immunochemistry, since the affinity and selectivity of a given antibody molecule can be tailored to meet the requirements of the envisaged analytical application. An efficient strategy for molecular antibody evolution is described that combines randomized point mutations and sequential recombination of variable antibody gene repertoires employing a group-selective library. This strategy enabled significant improvements in the binding of the model analyte atrazine that were monitored by both, kinetic measurements by the optical sensor BIAcore $2000^{\mathrm{TM}}$ and immunochemical key data obtained by enzyme-linked immunosorbent assay (ELISA). The $K_{\mathrm{D}}$ of the template antibody IPR-7 was improved by a factor of 17 from $1.27 \times 10^{-8} \mathrm{M}$ to $7.46 \times 10^{-10} \mathrm{M}$ for the optimized variant IPR-83. The enhanced $K_{\mathrm{D}}$ is well in line with the 15 fold lowered $\mathrm{IC}_{50}$ of the atrazine ELISA, which was shifted from $13.6 \mu \mathrm{g} / \mathrm{l}$ for IPR-7 to $0.9 \mu \mathrm{g} / \mathrm{l}$ for IPR-83. Once the analytical properties of antibody fragments are optimized, antibody functionality can be tailored for specific technical demands, e.g. the directed immobilization on microchip surfaces. As an example, the variable region encoding genes of the $\mathrm{scFv}$ variants were subcloned into the $\mathrm{F}_{\mathrm{ab}}$ fragment expression vector pASK99, in order to reconstitute the antigen binding site of native antibody molecules. The expressed $\mathrm{F}_{\mathrm{ab}}$ fragments provide a C-terminal affinity tag for functionalized sensor surfaces. Again, the evaluation by ELISA as well as by BIAcore revealed a consistent ratio of analyte binding enhancement for the engineered $F_{a b}$ fragments.
\end{abstract}

\section{Introduction}

Antibody engineering is a powerful tool for modifying antibody properties [1-3]. Antibody variable (V) genes encoding the antigen binding domains are modified in vivo during the secondary immune response in the microenvironment of lymphoid germinal centers by somatic hypermutation. Appropriate variants are subsequently selected from this pool of mutant immunoglobulins upon their improved affinity to the antigen [4]. A strategy for mimicking antibody maturation in vitro is based on the evolutionary concept of "variation and selection". Similar to the in vivo process, the antibody gene is diversified in an initial step by mutational procedures such as PCR based sequence randomization (c.f. Fig. 1). The mutated antibody gene repertoire is subsequently cloned into an expression vector and displayed at the protein level for instance on the surface of filamentous phage [5]. The surface presentation of the antibody phenotype enables the selection of improved variants, for example by their enhanced affinity to the antigen. Similar to the natural process, the in vitro evolution is an iterative process. Hence, improved antibody variants can be utilized as template structures for subsequent evolutionary cycles, until they meet the requirements of their designated application.

\footnotetext{
*Corresponding author. Tel.: +49 8161 713871; Fax: +49 8161 714403; E-mail: kramer@wzw.tum.de.
} 


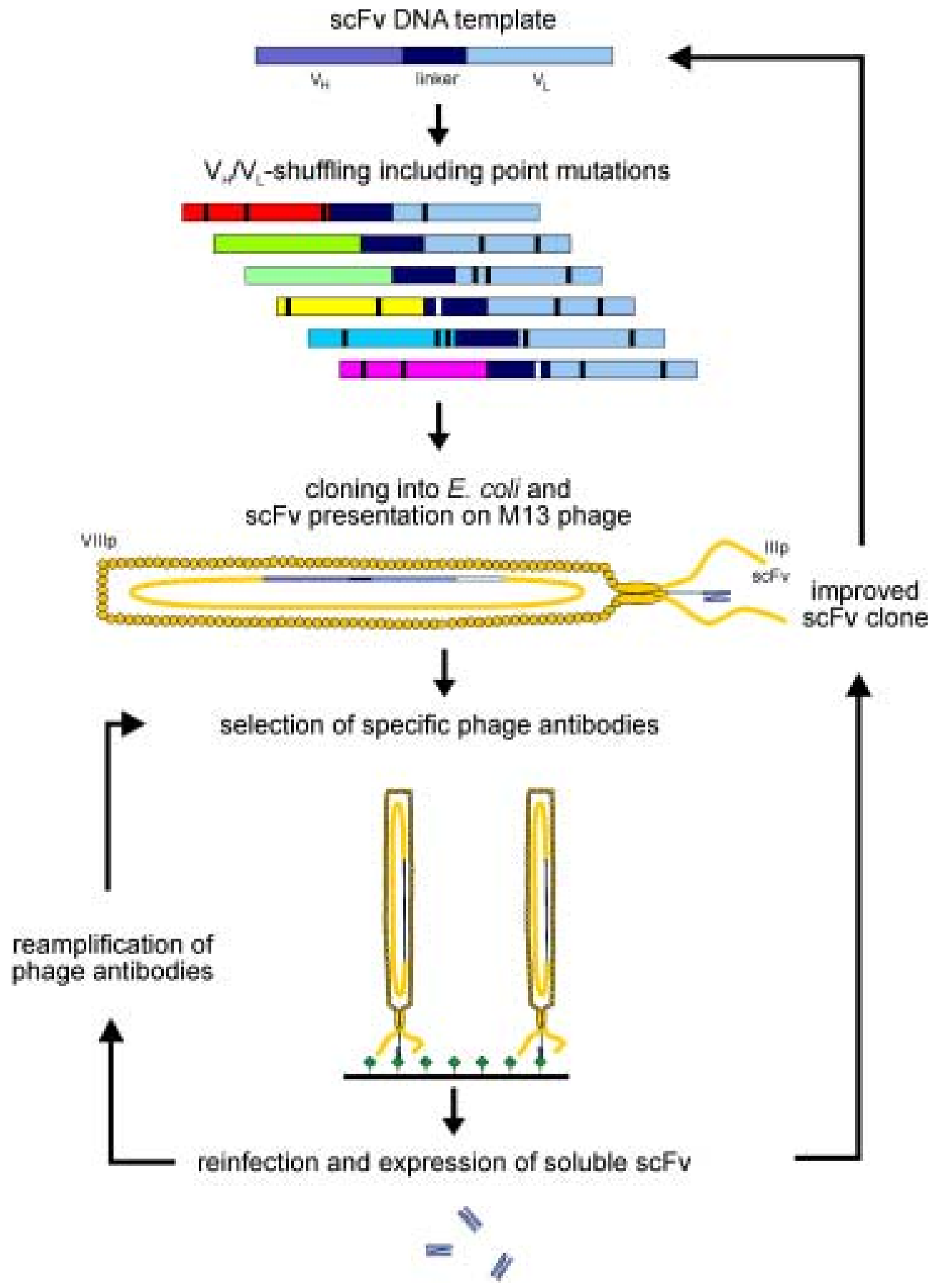

Fig. 1. Principle of molecular antibody evolution. The scFv antibody gene template is randomized by chain shuffling as indicated by $\mathrm{V}$ genes in different grey scales. Additional point mutations introduced by error prone PCR are depicted as vertical lines. 
The univocal and solid identification of improved variants is one of the key steps in molecular antibody evolution. In this paper, we compared two standard methods for the evaluation of the antibody binding properties applied in the field. The characterization of antibody variants for improved binding was performed in parallel by competitive enzyme-linked immunosorbent assay (ELISA) and by the surface plasmon resonance based optical sensor BIAcore $2000^{\mathrm{TM}}$. The ELISA was designed to deliver primarily analytical information such as the $\mathrm{IC}_{50}$ and detection limit of a calibration curve for a defined analyte, whereas the biosensor measurements provide kinetic rankings of the antibody variants.

The variable region encoding V genes of the single-chain Fv (scFv; c.f. Fig. 2) IPR-7 were utilized as template for affinity and selectivity maturation. IPR-7 has been isolated from a group-selective library that contains an increased percentage of $s$-triazine herbicide selective antibody genes [6]. This antibody fragment is characterized by its preferential binding to sebutylazine and a cross-reactivity of $74 \%$ to atrazine (c.f. Figs 3, 4). Sebutylazine is a herbicide of minor environmental relevance, whereas atrazine
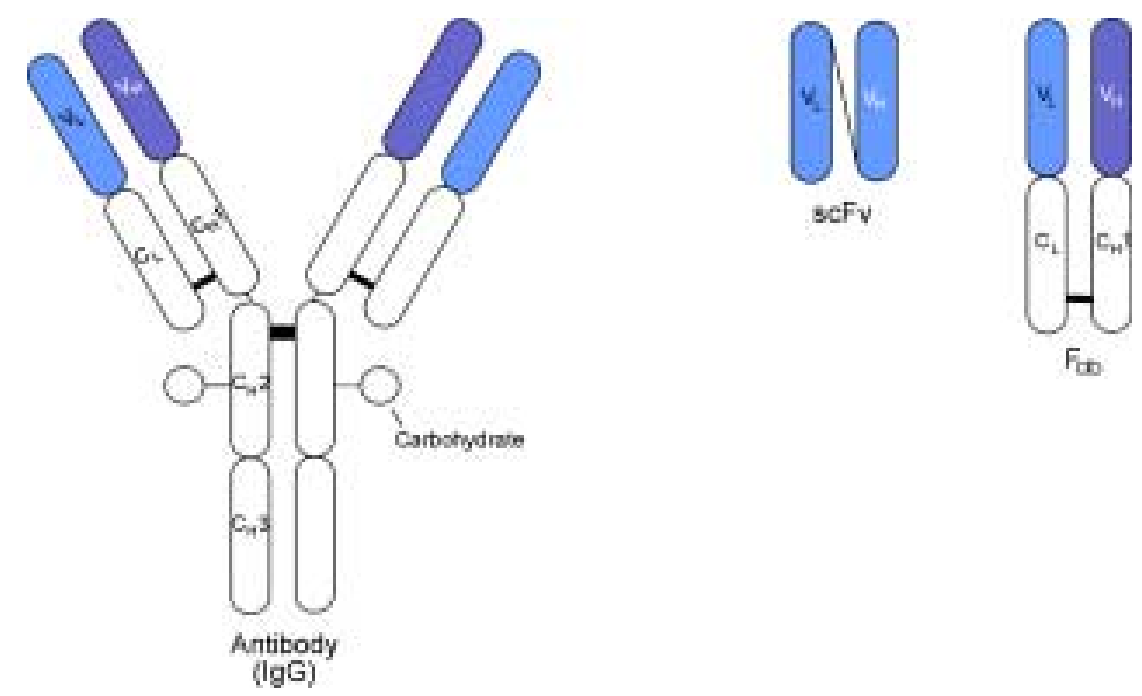

Fig. 2. Domain structure of a native antibody molecule ( $\mathrm{IgG}$ ), the corresponding recombinant single-chain $\mathrm{Fv}(\mathrm{scFv})$ and $\mathrm{F}_{\mathrm{ab}}$ fragment. The antigen binding domains $\mathrm{V}_{\mathrm{L}}$ and $\mathrm{V}_{\mathrm{H}}$ are depicted in grey.<smiles>CC(C)Nc1nc(Cl)nc(NCCCCC(=O)O)n1</smiles>

IPR
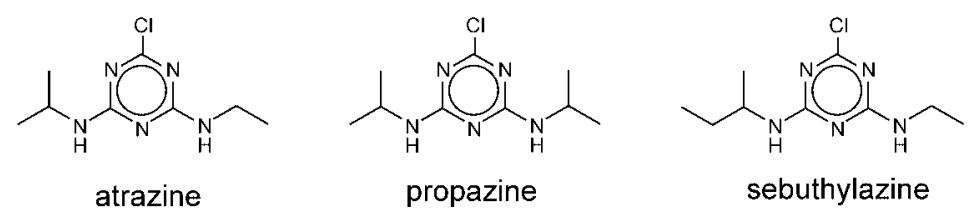

Fig. 3. Chemical structures of three $s$-triazine herbicides and the $s$-triazine derivative IPR (2-chloro-4-isopropylamino-6aminocaproic acid-1,3,5-triazine) that was applied for phage selection, surface coating of the CM5 biosensor chip and horseradish peroxidase tracer conjugate in the competitive ELISA. 


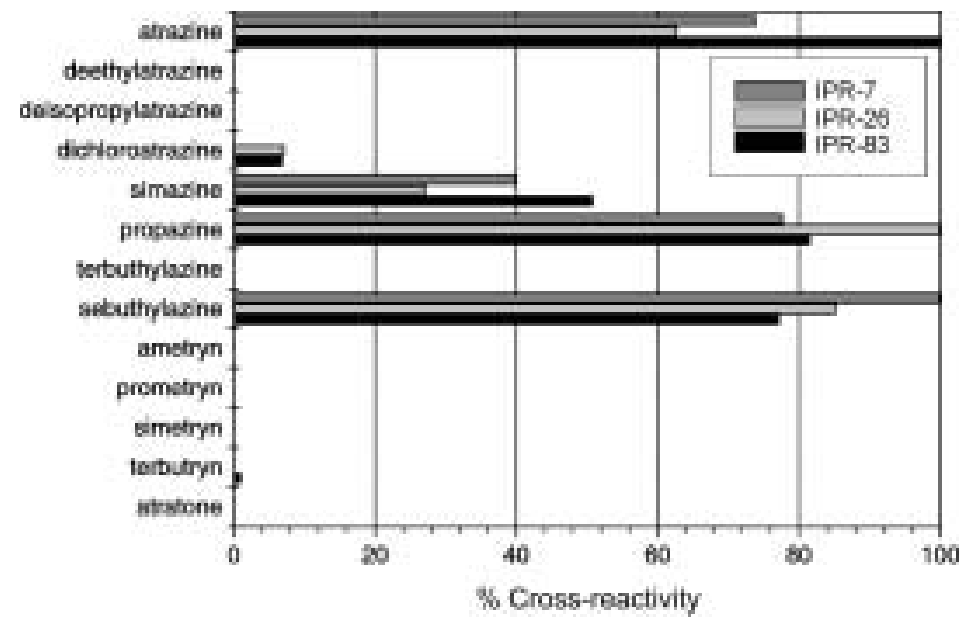

Fig. 4. Cross-reactivity of IPR-7 and $\mathrm{V}_{\mathrm{H} / \mathrm{L}}$-shuffled clones against 13 different triazines. Cross-reactivity for each clone is based individually on the analyte that is bound with the highest affinity. Cross-reactivity was determined according to the formula: $\%$ cross-reactivity $=(A / C) \times 100 \%$, where $A$ is the concentration of the analyte at $\mathrm{IC}_{50}$ and $C$ is the concentration of the cross-reacting triazine at $\mathrm{IC}_{50}$. Thus, IPR-7 was based on sebuthylazine ( $\left.\mathrm{IC}_{50}=17.75 \mu \mathrm{g} / \mathrm{l}\right)$, IPR-26 was based on propazine $\left(\mathrm{IC}_{50}=5.65 \mu \mathrm{g} / \mathrm{l}\right)$ and $\mathrm{IPR}-83$ was based on atrazine $\left(\mathrm{IC}_{50}=0.94 \mu \mathrm{g} / \mathrm{l}\right)$. Dichloroatrazine: 2,4-dichloro-6-isopropylamino-1,3,5-triazine.

is one of the most widely used herbicides in industrial countries like the US with a worldwide production rate of 70 kilotons per year. Therefore, the goal of the molecular optimization was to modify the antibody binding site to achieve a preferential recognition of the priority $s$-triazine herbicide atrazine (c.f. Fig. 3). In addition, the affinity level of the resulting antibody fragment should be significantly elevated to enable the development of a sensitive assay for atrazine analysis. Finally, the optimized $\mathrm{scFv}$ variants should be transformed into the $\mathrm{F}_{\mathrm{ab}}$ fragment format, in order to reconstitute the antigen binding site of native antibody molecules (c.f. Fig. 2).

\section{Variation of template antibody IPR-7 and selection of improved clones}

In order to randomize the antibody sequence of the template clone, the variable light chain $\left(\mathrm{V}_{\mathrm{L}}\right)$ of IPR-7 was shuffled against the variable heavy chain $\left(\mathrm{V}_{\mathrm{H}}\right)$ repertoire of a $s$-triazine group-selective antibody library [6] by PCR. Thus, the resulting scFvs comprised a broad panel of different $\mathrm{V}_{\mathrm{H}}$ genes from the group-selective library combined with the IPR- $7 \mathrm{~V}_{\mathrm{L}}$ gene, both bearing additional point mutations that were generated by error prone PCR (c.f. Fig. 1). The mutated $\mathrm{scFv}$ gene repertoire was then cloned into the phagemid vector pCANTAB 5E [7]. Transformation of the E. coli strain TG1 with the recombinant phagemid yielded a library of $1.9 \times 10^{7}$ transformed colonies.

Hapten-specific clones of the $\mathrm{V}_{\mathrm{H}}$-shuffled library were enriched by three repetitive cycles of selection applying immunoaffinity chromatography [8]. Phage displaying selective scFv were separated from nonselective phage by a passage through columns, which were packed with the IPR derivative (c.f. Fig. 3) coupled to sepharose beads via an alkyl spacer. Unbound phage were removed by washing and the IPRbound fraction was eluted thereafter by glycine-HCl. 


\section{Characterization of triazine-selective clones}

Soluble antibody fragments were expressed from an aliquot of 190 individual clones that were derived from the final, third phage selection cycle, and evaluated by ELISA for improved recognition of IPR-triazines. Six clones that exhibited improved binding and displacement by $s$-triazines containing isopropyl residues (i.e. atrazine and propazine, c.f. Fig. 3) were chosen for a detailed characterization, since these clones express mutant $\mathrm{scFv}$ with the highest sensitivity towards the target analyte as identified by ELISA. However, the six clones turned out to encode a single identical amino acid sequence designated as IPR-26. Alignment with germline genes (ImMunoGeneTics database [9]) revealed that the variable regions of IPR-26 belong to the $\mathrm{V}_{\mathrm{H}} 1$ and $\mathrm{V} \kappa 1$ gene family.

The hapten-antibody binding affinities of the initial clone IPR-7 and the shuffled derivative IPR-26 to the $s$-triazine derivative IPR were determined by employing the surface plasmon resonance based optical sensor BIAcore $2000^{\mathrm{TM}}$ system. The chip surface was prepared with $400 \mathrm{RU}$ covalently linked IPR-OVA. Ninety microliter of serial $\mathrm{scFv}$ concentrations (ranging from 1 to $50 \mathrm{nmol}$ ) of the individual antibody clones were injected and the sensorgrams were evaluated applying the BIA Evaluation 2.1 software. The binding was generally characterized by a low background signal that is due to small non-specific binding to OVA as observed in the control path during measurement. The dissociation equilibrium constant $K_{\mathrm{D}}$ of the affinity-purified $\mathrm{scFv}$ fragments was calculated from the association rate constant $k_{\mathrm{a}}$ and the dissociation rate constant $k_{\mathrm{d}}$ (Table 1). The equilibrium dissociation constant of $9.20 \times 10^{-9} \mathrm{M}$ of the $\mathrm{scFv}$ variant IPR-26 is approaching the typical $K_{\mathrm{D}}$ level in the lower nanomolar range of affinity matured antibodies in vivo [10].

In parallel to the kinetic characterization, IPR-26 was compared with IPR-7 by direct, competitive ELISA. Calibration curves were recorded with affinity-purified, monovalent $\mathrm{scFv}$ against a selection of 13 relevant triazines and utilized for the calculation of cross-reactivities (c.f. Fig. 4). The mutant scFv IPR-26 revealed a dominant recognition of propazine, a triazine herbicide containing two isopropyl residues (c.f. Fig. 3). The $\mathrm{IC}_{50}$ of IPR-26 for propazine was determined at $5.6 \mu \mathrm{g} / \mathrm{l}$ with a detection

Table 1

Association rate constant $k_{\mathrm{a}}$, dissociation rate constant $k_{\mathrm{d}}$ and equilibrium dissociation constant $K_{\mathrm{D}}$ for IPR obtained from the scFv clones IPR-7, IPR-26 and IPR-83. The values for $k_{\mathrm{a}}, k_{\mathrm{d}}$ and $K_{\mathrm{D}}$ were measured utilizing the BIAcore $2000^{\mathrm{TM}}$ system. Experimental: The IPR-ovalbumin (IPR-OVA) conjugate was immobilized on the CM5 chip by activating the carboxymethylated dextrane surface of the sensor with $35 \mu \mathrm{l}$ of a mixture of equal volumes of $\mathrm{N}$-hydroxysuccinimide $(0.1 \mathrm{M}$ in distilled water) and $\mathrm{N}$-(3-dimethylaminopropyl-)- $\mathrm{N}^{\prime}$-ethyl-carbodiimide-hydrochloride ( $0.1 \mathrm{M}$ in bidistilled water). IPR-OVA was dissolved in coupling buffer $(0.1 \mathrm{mg} / \mathrm{ml}$ in $10 \mathrm{mM}$ sodium acetate, $\mathrm{pH} 5)$ and injected at a constant flow of $10 \mu \mathrm{l} / \mathrm{min}$ until a specific surface of 400 resonance units (RU) was prepared $\left(1 \mathrm{RU}=1 \mathrm{ng} / \mathrm{mm}^{2}\right)$. Uncoupled carrier protein OVA was injected as a control in another flow channel of the same chip until the amount of immobilized OVA in the control channel was equivalent to the specific IPR-OVA surface. Residual NHS esters were deactivated by injecting $30 \mu \mathrm{l}$ of $1 \mathrm{M}$ ethanolamine, $\mathrm{pH}$ 8.5. For interaction analyses, different concentrations of each scFv clone (in $10 \mathrm{mM}$ PBS, pH 7.4) were injected for $3 \mathrm{~min}$ at a constant flow of $30 \mu \mathrm{l} / \mathrm{min}$ and $10 \mathrm{mM}$ PBS as the buffer stream. The buffer used for the kinetic measurements was composed of $10 \mathrm{mM}$ PBS, $2.7 \mathrm{mM}$ potassium chloride, $137 \mathrm{mM}$ sodium chloride, $\mathrm{pH} 7.4$ and $0.005 \%$ Tween 20 . The measurements were performed at $24^{\circ}$ C. Sensorgrams were evaluated with Bia Evaluation 2.1 software (BIAcore Ab, Uppsala, Sweden).

\begin{tabular}{lccc}
\hline Clone & $k_{\mathrm{a}}\left(\mathrm{M}^{-1} \mathrm{~s}^{-1}\right)$ & $k_{\mathrm{d}}\left(\mathrm{s}^{-1}\right)$ & $K_{\mathrm{D}}=k_{\mathrm{d}} / k_{\mathrm{a}}(\mathrm{M})$ \\
\hline IPR-7 & $1.38 \times 10^{5}$ & $1.75 \times 10^{-3}$ & $1.27 \times 10^{-8}$ \\
IPR-26 & $2.10 \times 10^{5}$ & $1.93 \times 10^{-3}$ & $9.20 \times 10^{-9}$ \\
IPR-83 & $6.73 \times 10^{5}$ & $5.02 \times 10^{-4}$ & $7.46 \times 10^{-10}$ \\
\hline
\end{tabular}




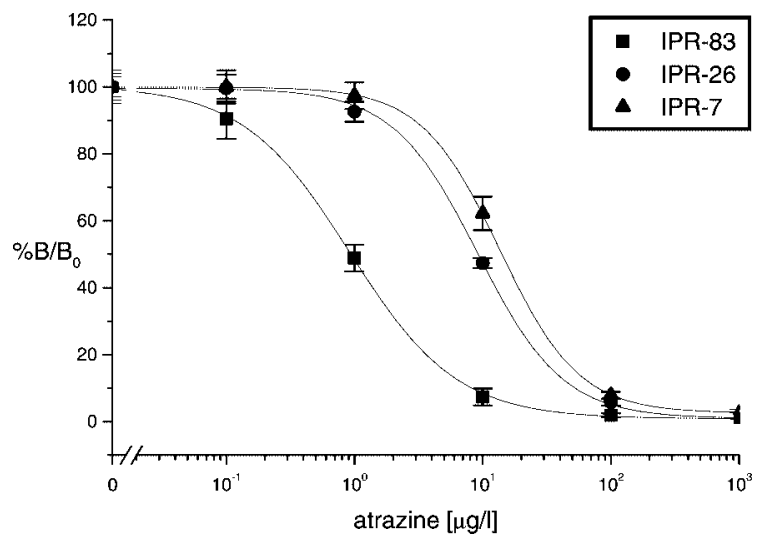

Fig. 5. Calibration curves of IPR-7 and $\mathrm{V}_{\mathrm{H} / \mathrm{L}}$-shuffled clones for the analysis of atrazine by direct, heterogeneous, competitive ELISA. The original curves, which are based on relative luminescence units (RLU), were normalized according to $\% B / B_{0}=\left(L-L_{\text {excess }}\right) /\left(L_{0}-L_{\text {excess }}\right)$, where $L$ is the luminescent signal, $L_{\text {excess }}$ the luminescent signal at excess of atrazine and $L_{0}$ the luminescent signal at zero dose of atrazine. $L_{0}$ corresponds to the maximum achieved signal of the calibration curve and was determined as 362 RLU for IPR-7, 647 RLU for IPR-26 and 407 RLU for IPR-83. $L_{\text {excess }}$ corresponds to the minimum achieved signal of the calibration curve and was determined as 61 RLU for IPR-7, 48 RLU for IPR-26 and 63 RLU for IPR-83. Experimental: Polystyrene microtiter plates (Greiner) were precoated overnight with $150 \mu \mathrm{l}$ of anti-E-tag antibody (Pharmacia; $5 \mu \mathrm{g} / \mathrm{ml}$ in carbonate buffer: $\mathrm{NaHCO}_{3} / \mathrm{Na}_{2} \mathrm{CO}_{3}, 50 \mathrm{mM}$, pH 9.6) at $4{ }^{\circ} \mathrm{C}$. All further reactions were carried out at room temperature. Following three wash steps with PBS-Tween 20 (4 mM phosphate-buffered saline, $\mathrm{pH} 7.2$, supplemented with $0.05 \%$ Tween 20 ), $150 \mu \mathrm{l}$ affinity-purified $\mathrm{scFv}$ were filled into each well. Unbound $\mathrm{scFv}$ was removed by rinsing three times with PBS-Tween 20 after $2 \mathrm{~h}$ incubation. Hundred $\mu \mathrm{l}$ of triazine standard or PBS were added together with $50 \mu \mathrm{l}$ enzyme tracer (IPR-horseradish peroxidase conjugate) and incubated for $1 \mathrm{~h}$. After a final washing step, $150 \mu \mathrm{l}$ of Super Signal ELISA Pico chemiluminescent substrate (Pierce) were pipetted into each well. The luminescence was measured after 5 min shaking incubation at $430 \mathrm{~nm}$ with a Tecan reader.

limit at $1.6 \mu \mathrm{g} / \mathrm{l}$ for this recombinant antibody fragment. Despite the preferential binding to propazine, IPR-26 exhibited a slightly improved assay sensitivity for the detection of atrazine as compared to the template antibody IPR-7 (c.f. Fig. 5). The IC $_{50}$ for atrazine shifted from $13.6 \mu \mathrm{g} / \mathrm{l}$ for IPR-7 to $9.1 \mu \mathrm{g} / \mathrm{l}$ for IPR-26. The detection limit defined as the atrazine concentration at $B / B_{0}=80 \%$ was thereby improved from $5.1 \mu \mathrm{g} / 1$ of IPR-7 to $3.2 \mu \mathrm{g} / \mathrm{l}$ of IPR-26. It should be noticed that the 1.4 fold improvement in $K_{\mathrm{D}}$ from IPR-7 to IPR-26 as determined by the kinetic measurements above is well in line with the 1.5 fold diminished $\mathrm{IC}_{50}$ and the 1.6 fold improved detection limit in the corresponding atrazine ELISAs.

\section{Variation of antibody derivative IPR-26 and selection of further enhanced antibody clones}

In order to further improve the affinity to $s$-triazines containing the isopropyl residue, the $\mathrm{V}_{\mathrm{H}}$ encoding gene of the selected clone IPR-26 was shuffled in a second round of diversification against the $\mathrm{V}_{\mathrm{L}}$ repertoire of the group-selective antibody library. Chain shuffling was performed essentially as outlined above. Again, $\mathrm{V}$ gene re-association was combined with point mutations that were introduced by error prone PCR. Thus, the resulting scFvs comprised a broad panel of different $\mathrm{V}_{\mathrm{L}}$ genes from the group-selective library combined with the IPR-26 $\mathrm{V}_{\mathrm{H}}$ gene bearing additional PCR generated point mutations. The mutated $\mathrm{scFv}$ gene repertoire was again cloned into the phagemid system yielding a library of $9.1 \times 10^{6}$ independent bacteria colonies. 


\section{Selection and characterization of improved, $V_{L}$-shuffled clones}

Phage selection and identification of improved clones was performed as described above. A selection of seven clones that exhibited improved binding and displacement by $s$-triazines containing isopropyl residues in a primary screening by ELISA were chosen for sequencing. Two different antibody sequences designated as IPR-23 and IPR-83 could be distinguished for these clones. Alignment with germline genes [9] revealed that the variable regions of the IPR clones belonged to the $V_{H} 1$ and $V \kappa 1$ gene family.

Thus, all of the selected IPR clones were assigned to the identical germline V genes IGVH1S2 and IGKV1-110 according to the IMGT data base [9]. Comparison of these germline V genes with the IPR clones revealed an augmented number of mutations from 24 through 26 amino acid substitutions in the heavy chain and from 9 to 13 amino acid substitutions in the light chain with proceeding evolutionary mutation level. The majority of the germline mutations in the heavy chain are located in the complementarity-determining regions CDR1 and CDR2 as well as in the adjacent frame work regions. Further germline mutations accumulated in the FR1 and CDR1 of the light chain gene (data not shown).

Cross-reactivities of IPR-23 and IPR-83 were again calculated from calibration curves obtained by ELISA. Since both clones did not reveal significant differences in their binding behavior to the tested triazines, only the cross-reactivity values of IPR-83 are detailed in Fig. 4. In the competitive ELISA this clone is preferentially displaced by atrazine, the target triazine herbicide that contains a single isopropyl residue. Thus, the optimization goal for the antibody selectivity was fully achieved. The $\mathrm{IC}_{50}$ of IPR-83 for atrazine was determined at $0.9 \mu \mathrm{g} / \mathrm{l}$ with a detection limit at $0.2 \mu \mathrm{g} / \mathrm{l}$ for this $\mathrm{scFv}$ (c.f. Fig. 5). The co-selected variant IPR-23 with an $\mathrm{IC}_{50}$ of $1.0 \mu \mathrm{g} / \mathrm{l}$ and a detection limit at $0.2 \mu \mathrm{g} / \mathrm{l}$ showed no significant deviation from the values obtained with IPR-83 within the experimental error. Thereby, the detection limit of the mutant scFv IPR-83 and IPR-23 was improved 25-fold as compared to the initial template antibody IPR-7. Simultaneously, the cross-reactivity pattern to $s$-triazines indicates a shift towards atrazine as the dominant analyte, followed by propazine.

Kinetic characteristics of IPR-83 were determined by surface plasmon resonance (BIAcore 2000) according to the procedure described above. The kinetic data of this scFv variant are detailed in Table 1. The molecular evolution from IPR-26 to IPR-83 resulted in a 12.3 fold reduction of the $K_{\mathrm{D}}$, which is mirrored by a 10.1 fold decrease of the $\mathrm{IC}_{50}$ atrazine concentration and a 16.0 fold decline of the detection limit in the corresponding ELISA (c.f. Fig. 5). The overall improvement in the $K_{\mathrm{D}}$ from the template antibody IPR-7 to the optimized variant IPR- 83 by a factor of 17 is almost consistent with the 15 fold lowered atrazine concentration for the $\mathrm{IC}_{50}$. The detection limit was even 25 fold diminished.

The slight alteration in $K_{\mathrm{D}}$ from IPR-7 to IPR-26 is mainly due to an increased association rate constant $k_{\mathrm{a}}$. In contrast, the significant shift in $K_{\mathrm{D}}$ from IPR-26 to IPR-83 is caused by an increase in $k_{\mathrm{a}}$ and a concomitant decrease of $k_{\mathrm{d}}$. This result might be surprising in the first instance, since improved antibody affinity is frequently caused by a reduced dissociation rate constant $k_{\mathrm{d}}$. However, the alteration of the binding kinetics of the antibody variants described in this paper are most likely a consequence of the applied selection strategy. In order to isolate improved clones from the shuffled pool of antibody variants, the stringency was successively raised for both, faster association and slower dissociation rate of the antibody fragments to the IPR-derivative.

\section{Molecular transformation from $s c F v$ into $F_{a b}$ antibody fragment format}

In order to obtain recombinant antibody fragments lacking the scFv peptide linker and thus reconstituting an antigen binding site of natural antibody molecules, the variable heavy $\left(\mathrm{V}_{\mathrm{H}}\right)$ and light chain $\left(\mathrm{V}_{\mathrm{L}}\right)$ 


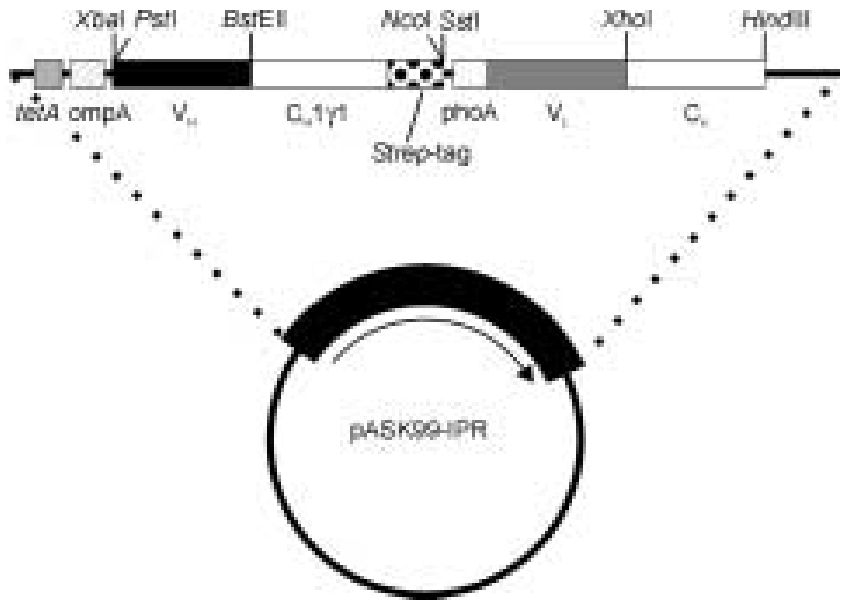

Fig. 6. pASK99-IPR expression plasmid. The plasmid was kindly provided by Prof. A. Skerra, Lehrstuhl für Biologische Chemie, Center of Life Sciences Weihenstephan, Technische Universität München, Germany. Schematic representation of the vector pASK99 after the transfer of genes for the variable light $\left(\mathrm{V}_{\mathrm{L}}\right)$ and heavy chain $\left(\mathrm{V}_{\mathrm{H}}\right)$ regions from scFv encoding pCANTAB 5E. The vector incorporates the genes for the constant heavy $\left(\mathrm{C}_{\mathrm{H}} 1 \gamma 1\right)$ and light chain $(\mathrm{C} \kappa)$ regions for construction and expression of $\mathrm{F}_{\mathrm{ab}}$ fragments in the periplasm of E. coli. $\mathrm{F}_{\mathrm{ab}}$ expression is under transcriptional control of the tet $\mathrm{A}$ promoter. OmpA and phoA indicate the ompA leader and the phoA leader, respectively. Strep tag represents the peptide encoding sequence for the streptavidin affinity tag [11]. The restriction enzymes PstI, BstEII, SstI and XhoI were used for inserting the variable region genes and $\mathrm{XbaI}, \mathrm{NcoI}$, SstI and HindIII for ligating the heavy and light chain fragments with pASK99.

domains of the three scFv variants IPR-7, IPR-26 and Ipr-83 were cloned into the $\mathrm{F}_{\mathrm{ab}}$ expression vector pASK99 (Fig. 6). This vector contains the murine heavy $\left(\mathrm{C}_{\mathrm{H}} 1 \gamma 1\right)$ and light chain $\left(\mathrm{C}_{\kappa}\right)$ constant regions of mouse immunoglobulin $\mathrm{G}(\mathrm{IgG})$. The $\mathrm{V}_{\mathrm{H}}$ and $\mathrm{V}_{\mathrm{L}}$ genes were isolated from $\mathrm{scFv}$ harbouring pCANTAB $5 \mathrm{E}$ phagemids by PCR. The corresponding primers were designed to anneal within the flanking regions of a whole set of murine variable genes - thus providing a generic approach. Subcloning was facilitated by using three restriction enzyme recognition sites, which are frequently conserved in antibody framework regions. The fourth restriction site $X$ hoI that was needed for insertion into pASK99, was introduced at the $3^{\prime}$-end of $\mathrm{V}_{\mathrm{L}}$ by the corresponding PCR primer. The amplified $\mathrm{V}$ genes were digested and inserted into the plasmid vector pASK99 in order to obtain full-length $\mathrm{F}_{\mathrm{ab}}$ genes. Functional $\mathrm{F}_{\mathrm{ab}}$ fragments were expressed in transformed $E$. coli and purified via streptavidin-affinity chromatography [11].

\section{Characterization of $\mathbf{F}_{\mathbf{a b}}$ antibody fragments}

Following Strep-tag affinity purification, the eluted fractions were analysed by SDS-PAGE under reducing and non reducing conditions (c.f. Fig. 7). The heavy and light chains of the reduced $F_{a b}$ fragments appeared in equimolar amounts with a size of c. 20-25 kD. The non-reduced $\mathrm{F}_{\mathrm{ab}}$ fragments revealed a size about $40 \mathrm{kD} . \mathrm{F}_{\mathrm{ab}}$ containing fractions were pooled and characterized according to the parent $\mathrm{scFv}$ fragments.

The functionality of the generated $F_{a b}$ variants were again examined in a direct, competitive ELISA (c.f. Fig. 8). The key values of the atrazine calibration curves are as follows: The $\mathrm{IC}_{50}$ of the $\mathrm{F}_{\mathrm{ab}}$ variants were calculated at $60.5 \mu \mathrm{g} / \mathrm{l}$ for $\mathrm{F}_{\mathrm{ab}}$ IPR-7, $15.2 \mu \mathrm{g} / \mathrm{l}$ for $\mathrm{F}_{\mathrm{ab}}$ IPR-26 and $2.7 \mu \mathrm{g} / \mathrm{l}$ for $\mathrm{F}_{\mathrm{ab}}$ IPR-83. The corresponding detection limits $\left(\mathrm{IC}_{80}\right)$ were determined at $14.9 \mu \mathrm{g} / \mathrm{l}, 5.7 \mu \mathrm{g} / \mathrm{l}$ and $0.13 \mu \mathrm{g} / \mathrm{l}$ for $\mathrm{F}_{\mathrm{ab}}$ IPR-7, $\mathrm{F}_{\mathrm{ab}}$ IPR-26 and $\mathrm{F}_{\mathrm{ab}}$ IPR-83, respectively. The $\mathrm{IC}_{50}$ and the $\mathrm{IC}_{80}$ values reflected the evolutionary 


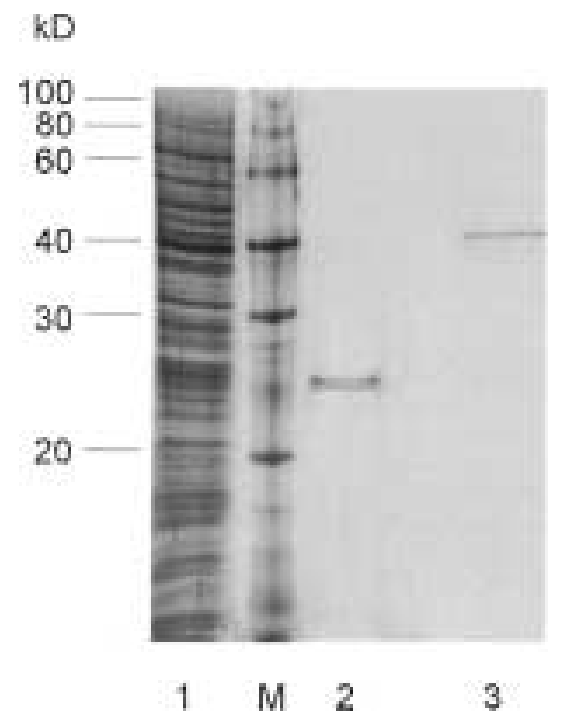

Fig. 7. SDS-PAGE of bacterial protein fractions. Lane 1: Periplasmic cell fraction. M: Molecular mass marker. Lane 2: $F_{a b}$ fragment eluted during streptavidin-affinity chromatography, reduced, revealing its light and heavy chain. Lane $3: \mathrm{F}_{\mathrm{ab}}$ fragment eluted during streptavidin-affinity chromatography, with the disulfide bond between the two chains not reduced prior to gel electrophoresis.

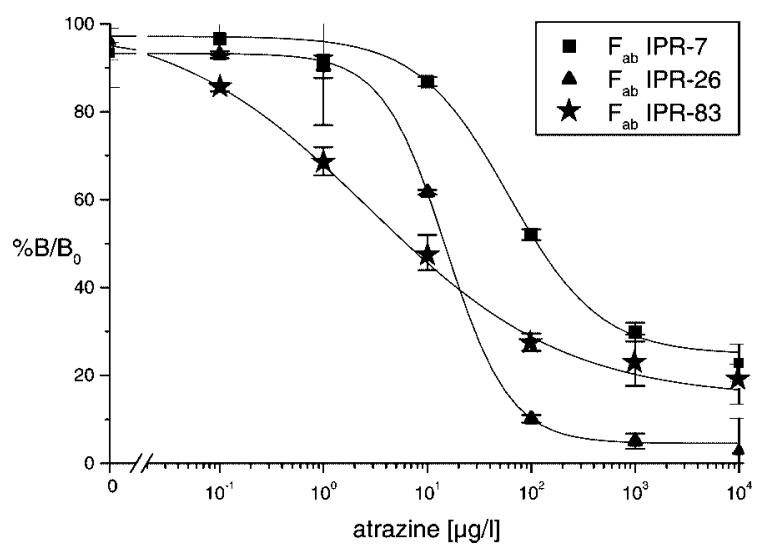

Fig. 8. Calibration curves of the $s$-triazine selective $\mathrm{F}_{a b}$ variants $\mathrm{F}_{\mathrm{ab}}$ IPR-7, $\mathrm{F}_{\mathrm{ab}}$ IPR-26 and $\mathrm{F}_{\mathrm{ab}}$ IPR-83. The curves were determined in a direct, competitive ELISA basically according to the $\mathrm{scFv}$ calibration curves shown in Fig. 4. However, $\mathrm{F}_{a b}$ fragments were immobilized at the microtiter plate by goat-anti-mouse IgG instead of the anti-E-tag antibody.

modified binding characteristics of the $\mathrm{F}_{\mathrm{ab}}$ mutants as also indicated by the $\mathrm{IC}_{50}$ and the $\mathrm{IC}_{80}$ values of the corresponding $\mathrm{scFv}$ fragments (c.f. Table 1).

The binding properties of the $\mathrm{F}_{\mathrm{ab}}$ fragments to the $s$-triazine derivative IPR were further examined by employing the BIAcore $2000^{\mathrm{TM}}$ system as already described above. The association rate constant $k_{\mathrm{a}}$, dissociation rate constant $k_{\mathrm{d}}$ and equilibrium dissociation constant $K_{\mathrm{D}}$ of the three $\mathrm{F}_{\mathrm{ab}}$ variants are detailed in Table 2 . The equilibrium dissociation constants of the $\mathrm{F}_{\mathrm{ab}}$ variants are roughly approaching the $K_{\mathrm{D}}$ level of the corresponding parent scFv fragments. The 1.8 fold improvement in $K_{\mathrm{D}}$ from IPR-7 to IPR-26 meets the order of magnitude of the 4 fold diminished $\mathrm{IC}_{50}$ and the 2.6 fold decreased detection limit in the atrazine ELISA. The subsequent molecular evolution from IPR-26 to IPR-83 resulted in a 13.7 
Table 2

Association rate constant $k_{\mathrm{a}}$, dissociation rate constant $k_{\mathrm{d}}$ and equilibrium dissociation constant $K_{\mathrm{D}}$ of the $s$-triazine selective $\mathrm{F}_{\mathrm{ab}}$ fragments obtained from the clones IPR-7, IPR-26 and IPR-83. The values for $k_{\mathrm{a}}, k_{\mathrm{d}}$ and $K_{\mathrm{D}}$ were measured by BIAcore $2000^{\mathrm{TM}}$ as described in the legend of Table 1

\begin{tabular}{lccc}
\hline Clone & $k_{\mathrm{a}}\left(\mathrm{M}^{-1} \mathrm{~s}^{-1}\right)$ & $k_{\mathrm{d}}\left(\mathrm{s}^{-1}\right)$ & $K_{\mathrm{D}}=k_{\mathrm{d}} / k_{\mathrm{a}}(\mathrm{M})$ \\
\hline IPR-7 & $9.72 \times 10^{4}$ & $2.65 \times 10^{-3}$ & $2.73 \times 10^{-8}$ \\
IPR-26 & $1.85 \times 10^{5}$ & $2.83 \times 10^{-3}$ & $1.53 \times 10^{-8}$ \\
IPR-83 & $5.49 \times 10^{5}$ & $6.17 \times 10^{-4}$ & $1.12 \times 10^{-9}$ \\
\hline
\end{tabular}

fold reduction of the $K_{\mathrm{D}}$, which is in the order of magnitude of the 5.6 fold decrease of the $\mathrm{IC}_{50}$ atrazine concentration and the 43.8 fold decline of the detection limit. In contrast, the overall improvement in the $K_{\mathrm{D}}$ from IPR-7 to IPR- 83 by a factor of 24 is well compared to the 22 fold lowered atrazine concentration for the $\mathrm{IC}_{50}$. The detection limit was even 115 fold diminished. The deviations revealed here are mainly due to the significantly altered steepness of the $\mathrm{F}_{\mathrm{ab}}$ IPR- 83 calibration curve for the detection of atrazine (c.f. Fig. 8).

The biosensor set-ups showed that the $\mathrm{F}_{\mathrm{ab}}$ antibody fragments bind IPR-OVA with a high selectivity. The comparison of the kinetic data of the IPR clones in the $\mathrm{scFv}$ with the $\mathrm{F}_{\mathrm{ab}}$ format did generally reveal a bias towards slightly improved $K_{\mathrm{D}}$ values for the $\mathrm{scFv}$ fragments. This is consistent with the ELISA data, where the variants were characterized by lower $\mathrm{IC}_{50}$ concentrations in the $\mathrm{scFv}$ format as compared to the $\mathrm{F}_{\mathrm{ab}}$ fragments.

\section{Conclusions}

Molecular evolution of antibody fragments as well as the transformation from one molecular format to another paves the way for tailored binding molecules, that can be optimised for various analytical applications. The molecular evolution of antibody affinity can be monitored by various techniques. The degree of the individual levels of evolutionary affinity enhancement was evaluated by competitive ELISA as well as by the BIAcore $2000^{\mathrm{TM}}$ system with appropriate consistency - at least in a relative manner. Therefore, both evaluation methods seem to provide adequate measures for the evolutionary optimisation of antibody molecules.

\section{Acknowledgements}

We thank Prof. Arne Skerra (Lehrstuhl für Biologische Chemie, Center of Life Sciences Weihenstephan, Technische Universität München, Germany) for providing the expression vector pASK99 and the purification material for the streptavidin-affinity chromatography. Part of this work was supported by the Deutsche Forschungsgemeinschaft (HO 383/35-1/2).

\section{References}

[1] E.T. Boder, K.S. Midelfort and K.D. Wittrup, Directed evolution of antibody fragments with monovalent femtomolar antigen-binding affinity, Proc. Natl. Acad. Sci. USA 97 (2000), 10 701-10 705.

[2] P.S. Daugherty, G. Chen, B.L. Iverson and G. Georgiou, Quantitative analysis of the effect of the mutation frequency on the affinity maturation of single chain Fv antibodies, Proc. Natl. Acad. Sci. USA 97 (2000) 2029-2034. 
[3] J. Hanes, C. Schaffitzel, A. Knappik and A. Plückthun, Picomolar affinity antibodies from a fully synthetic naive library selected and evolved by ribosome display, Nature Biotechnol. 18 (2000), 1287-1292.

[4] K. Rajewsky, Clonal selection and learning in the antibody system, Nature 381 (1996), 751-758.

[5] G.P. Smith and J.K. Scott, Libraries of peptides and proteins displayed on filamentous phage, Methods Enzymol. 217 (1993), 228-257.

[6] K. Kramer, Synthesis of a group-selective antibody library against haptens, J. Immunol. Meth. 266 (2002), $209-220$.

[7] J.A. Malone, pCANTAB 5E: A vector designed for the expression of antibody F variable regions as phage displayed or soluble single-chain proteins (scFv), Direct submission, Pharmacia Biotech Inc., 1994.

[8] T. Kretschmar, C. Zimmermann and M. Geiser, Selection procedures for nonmatured phage antibodies: A quantitative comparison and optimization strategies, Anal. Biochem. 224 (1995), 413-419.

[9] M.-P. Lefranc, Unique database numbering for immunoglobulins, T cell receptors and Ig-like domains, The Immunologist 7 (1999), 132-136.

[10] G. Winter, A.D. Griffths, R.E. Hawkins and H.R. Hoogenboom, Making antibodies by phage display technology, Annu. Rev. Immunol. 12 (1994), 433-455.

[11] T.G.M. Schmidt and A. Skerra, One-step affinity purification of bacterially produced proteins by means of the "strep tag" and immobilized recombinant core streptavidin, J. Chromatog. A 676 (1994), 337-345. 


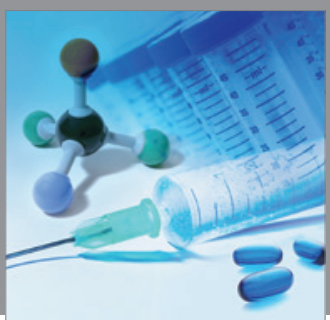

International Journal of

Medicinal Chemistry

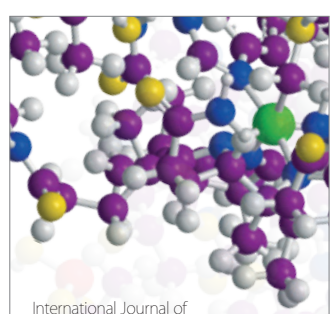

Carbohydrate Chemistry

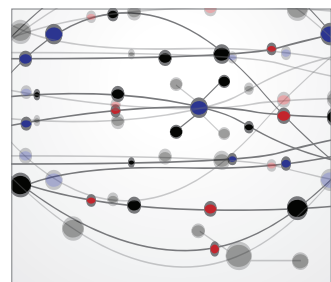

The Scientific World Journal
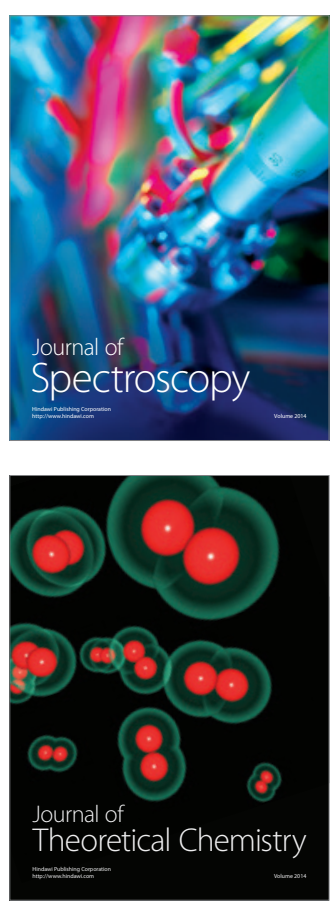
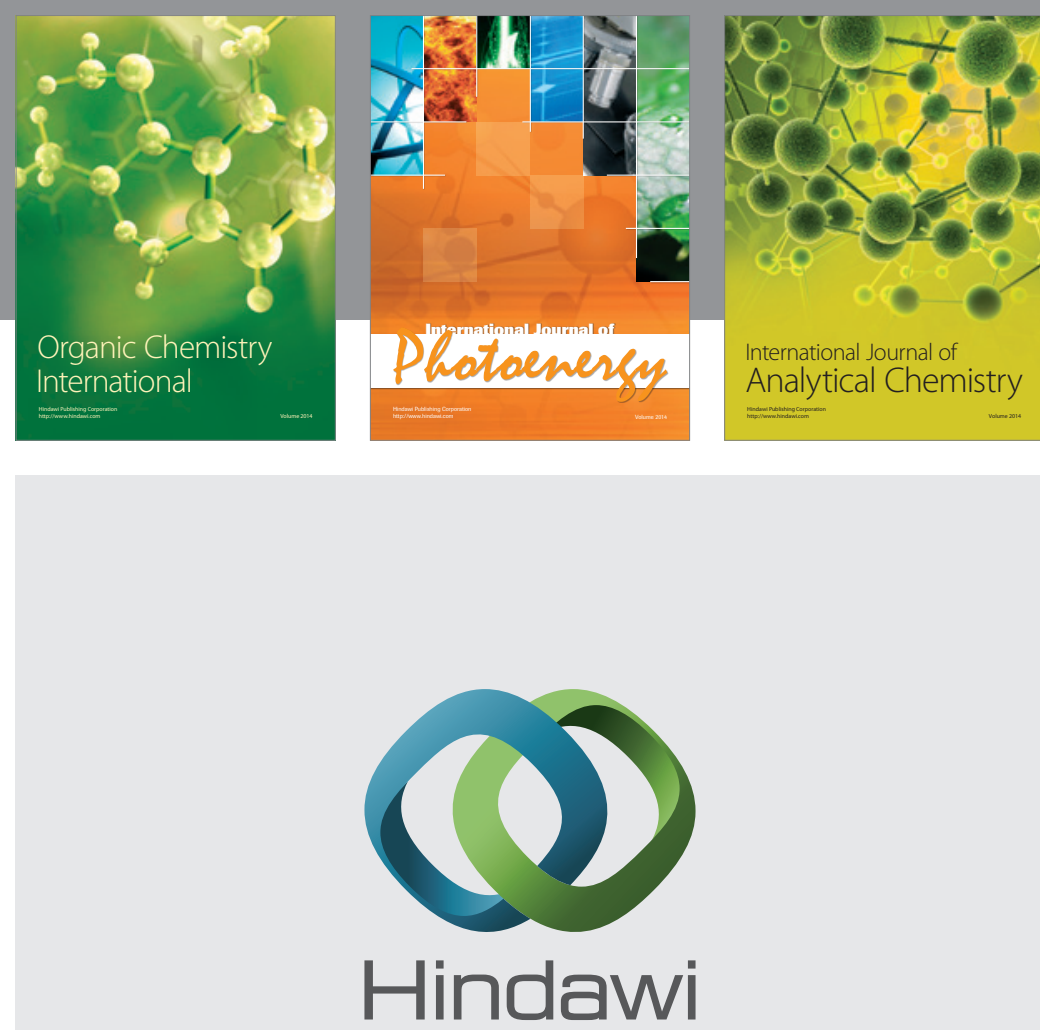

Submit your manuscripts at

http://www.hindawi.com
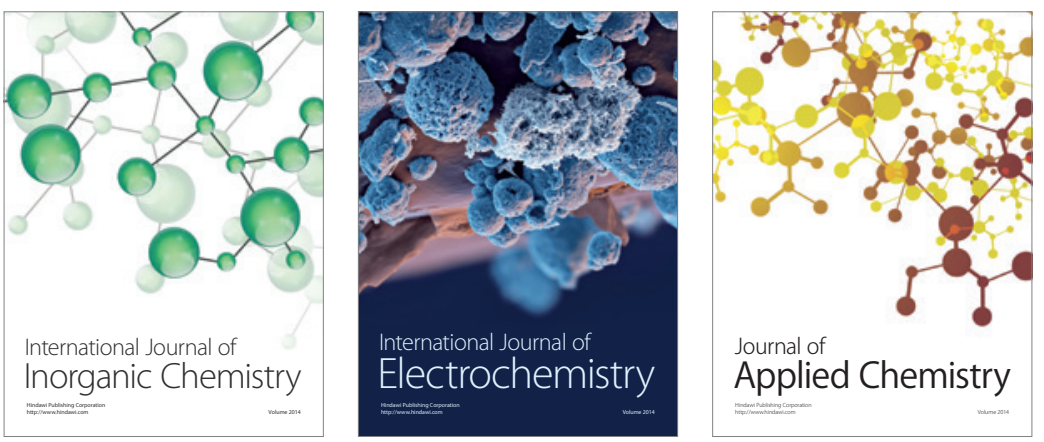

Journal of

Applied Chemistry
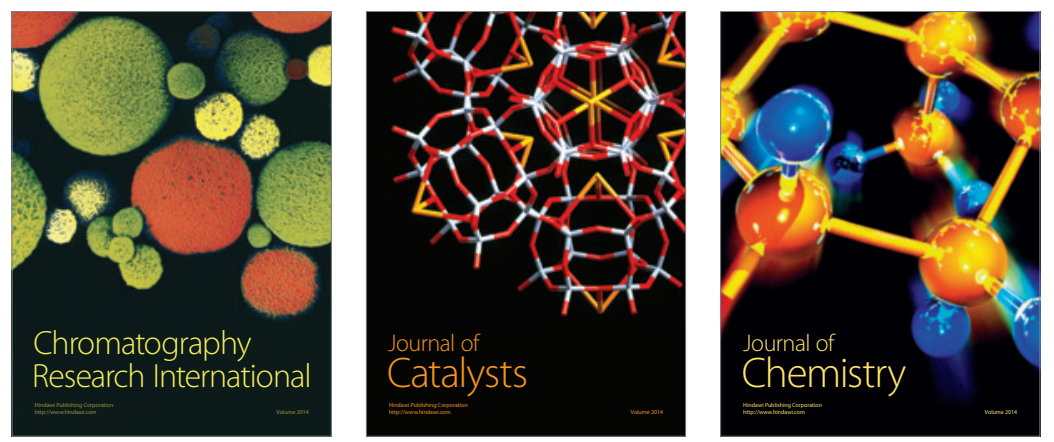
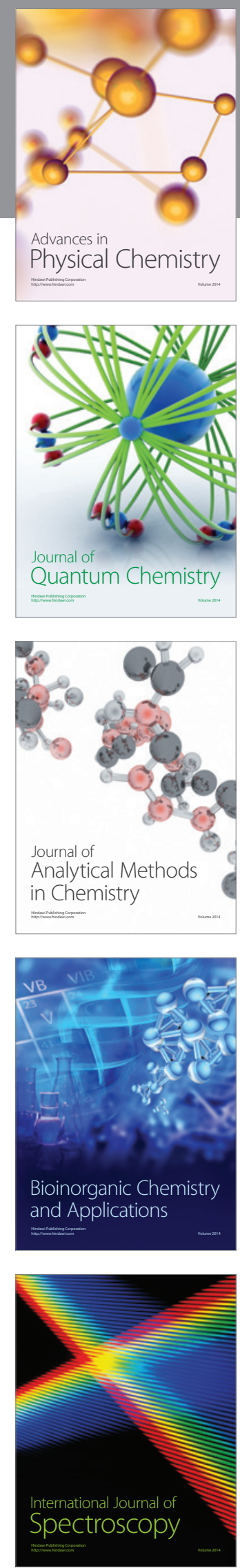